\title{
CASO 3-2013: Femenina 13 años con Nevus Piloso Gigante
}

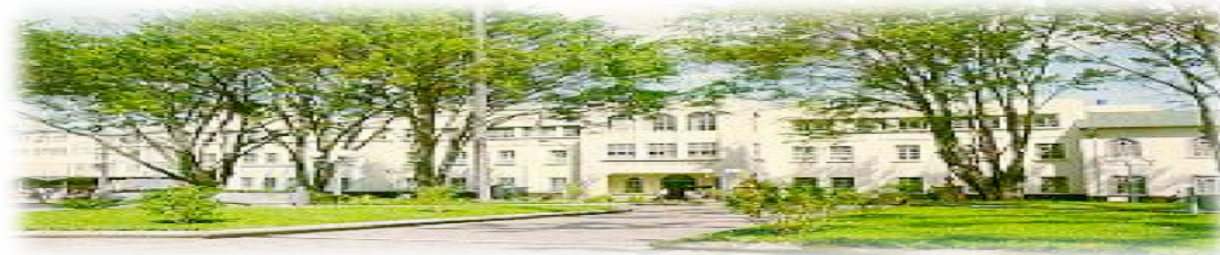

Hospital San Juan de Dias. San José. Costa Rica. Fundado en 1845

\section{Reporte de Caso y Descripción del Tratamiento Quirúrgico}

Recibido: $\quad 22 / 02 / 2013$

Aceptado: $\quad 20 / 03 / 2013$

Giovanni Montoya Mora ${ }^{1}$

Loretta Piccolo Johanning ${ }^{2}$

${ }^{1}$ Médico Asistente Especialista en Cirugía Plástica, Estética y Reconstructiva. Hospital CIMA, San José. Correo electrónico: gmontoya@hospitalcima.com

${ }^{2}$ Médica Cirujana. Hospital CIMA, San José. Correo electrónico: 1piccolo@medicos.cr

\section{RESUMEN}

Paciente femenina de 13 años de edad sin antecedentes patológicos conocidos, quien consultó por lesión dérmica consistente con nevus piloso gigante en la zona lumbar. Luego de 6 intervenciones quirúrgicas y con la ayuda de expansores tisulares, dicha lesión fue resecada en su totalidad.

\section{PALABRAS CLAVE}

Expansores tisulares. Nevus Piloso Gigante.

\section{ABSTRACT}

A 13 years-old female patient, without previous medical conditions. She complained of a giant hairy nevus lesion on her lower back. After 6 surgical procedures it is fully resected, with the help of tissue expanders.

\section{KEY WORDS}

Tissue Expanders. Giant Hairy Nevus. 


\section{CASO CLÍNICO}

Femenina de 13 años, estudiante, sin antecedentes médicos conocidos. Consultó en setiembre de 2002 por un nevus piloso gigante en la región lumbar, de 68 x $98 \mathrm{~cm}$ (Figura 1). Se decidió colocar expansores tisulares, para al final poder resecar la lesión, en varios tiempos quirúrgicos.

Figura 1. Nevus piloso gigante previo a tratamiento.

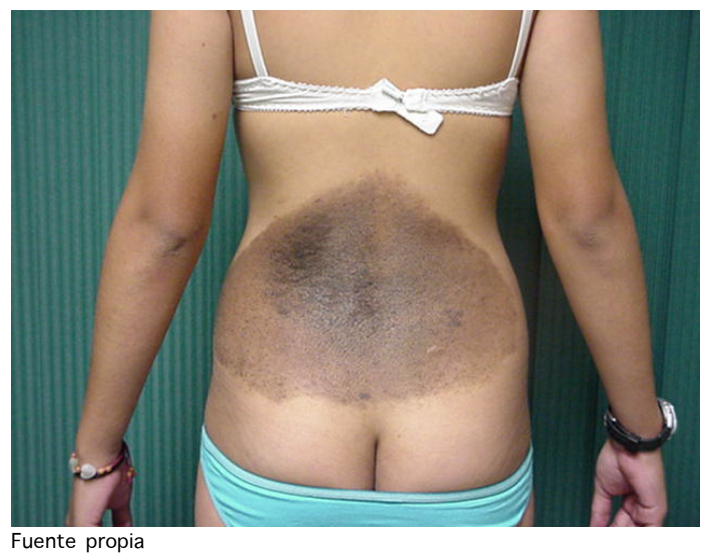

En la primera intervención quirúrgica se colocó 4 expansores tisulares rectangulares de $800 \mathrm{cc}$ cada uno, en regiones subescapulares y en regiones glúteas (Figura 2).

Figura 2. Colocación de expansores tisulares en sala de operaciones.

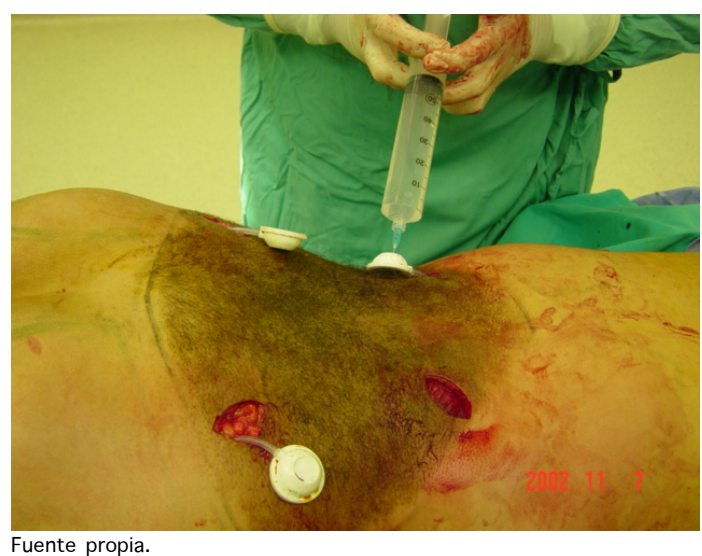

En un periodo de aproximadamente 2 meses se realizó infiltraciones semanales seriadas con solución fisiológica ( 80 a 180 cc cada una), a través de las válvulas (puertos) de los expansores, variando la cantidad por expansor y por sesión (Figura 3).

Figura 3. Expansores tisulares colocados en regiones subscapular y regiones glúteas en proceso infiltración.

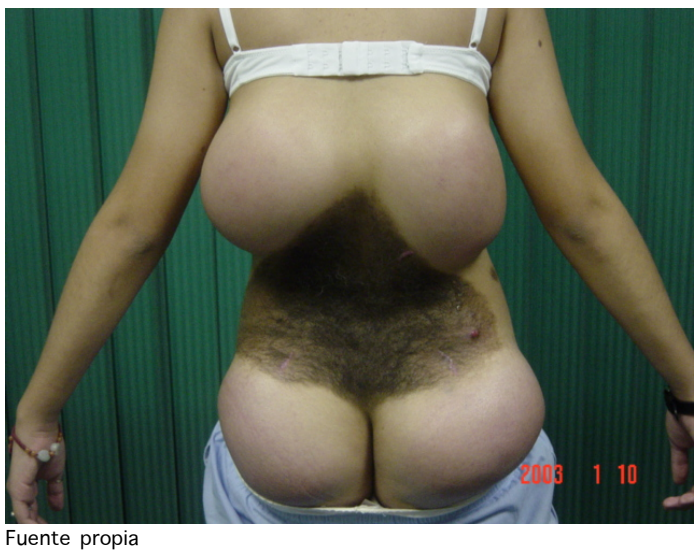

En la segunda operación, redujo el nevus en un $60 \%$ (Figuras 4 A y B.). La biopsia de la lesión reportó: "Nevus Piloso Gigante + Zona de Inflamación Aguda y Crónica".

Un mes después de la intervención, las válvulas superiores se desajustaron, por lo que fue llevada de nuevo a cirugía. En dicha intervención, se cambió los expansores derechos superior e inferior. Al pasar un mes se reinició con las expansiones semanales con solución fisiológica, de aproximadamente $150 \mathrm{cc}$ cada vez (inicialmente $240 \mathrm{cc}$ ). Dos meses después se programó para una nueva cirugía.

En la cuarta intervención quirúrgica, 9 meses posterior a la consulta inicial, se resecó un $95 \%$ del nevus. Evolucionó satisfactoriamente, sin embargo presentó un seroma en la región lumbar, que se drenó en distintas ocasiones.

Seis meses después se realizó plastía de las cicatrices hipertróficas, se resecó el sobrante del nevus y se irradió la zona afectada.

De esta quinta operación evolucionó sin complicaciones y completó los ciclos respectivos de radioterapia. 
Cinco años después de la consulta inicial, se intervino quirúrgicamente por sexta vez, para liposucción e injerto graso en glúteos.

Figura 4. A) Remoción de aproximadamente $60 \%$ de la lesión en sala de operaciones. B) Resultado de dicha intervención.

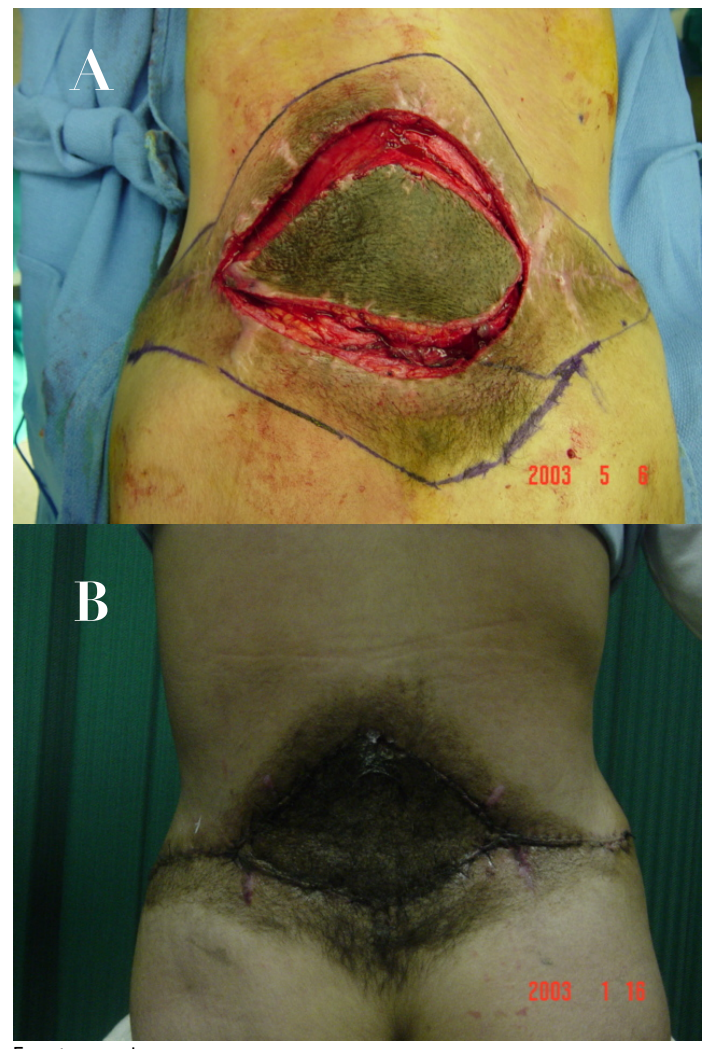

Fuente propia.

En noviembre de 2007, a cinco años de su consulta inicial y tras someterse a seis cirugías reconstructivas, fue dada de alta (Figura 5).

\section{DISCUSIÓN}

El nevus piloso es un tumor benigno del sistema pigmentario cutáneo ${ }^{(1)}$. Consiste en una placa pigmentada, con pelos gruesos y pequeños nódulos de distinta composición ${ }^{(2)}$.

$\mathrm{Su}$ forma varía de redondeado a ovalado, con superficie lisa, rugosa o verrugosa y puede estar bien definido o tener bordes irregulares, ser cerebriforme o lobular ${ }^{(2,3,5,6)}$.
Figura 5. Resultado final luego de resección completa del nevus.

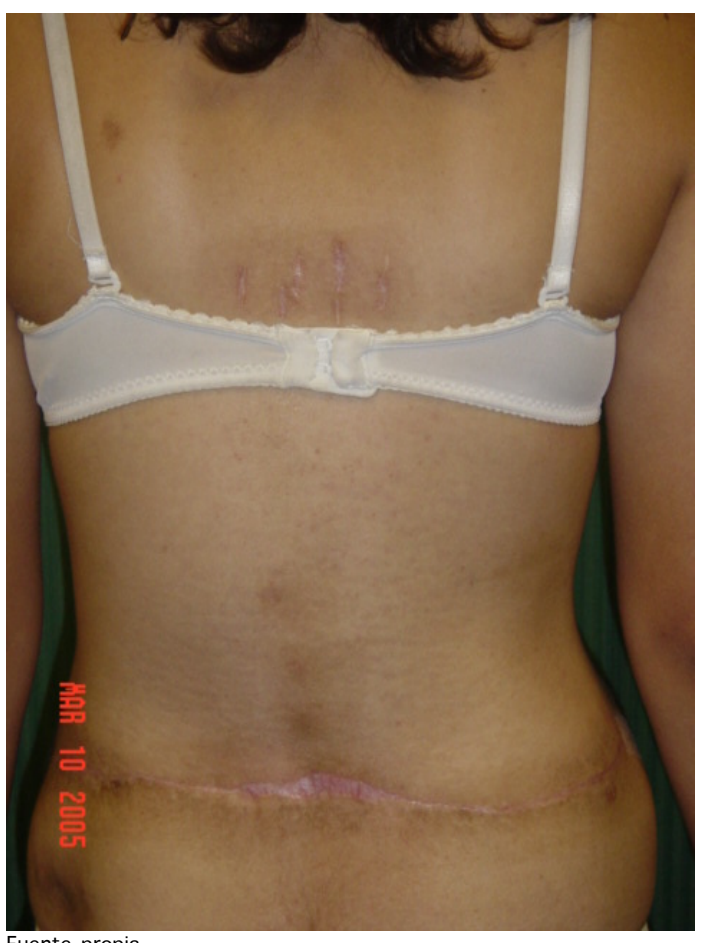

Fuente propia.

Existen varios criterios para considerar la lesión como gigante, entre los que se encuentran: ser mayor de $20 \mathrm{~cm}$, mayor del $30 \%$ de la superficie corporal o tener el tamaño de la palma de la mano en cara o el doble en otras zonas ${ }^{(2,3,6,7)}$.

Se ha demostrado una relación entre el nevus piloso gigante y el melanoma, principalmente en aquellos nevus que afectan más del $5 \%$ de la superficie corporal $^{(2)}$, variando dicho riesgo de malignización según la serie epidemiológica del 4 al $42 \%{ }^{(3,6,8)}$.

Sin embargo, el diagnóstico precoz del melanoma dentro de un nevus gigante presenta cierto grado de dificultad debido al color negruzco de ambas lesiones, por esto, los signos de transformación maligna suelen ser tardíos y acompañados por metástasis ${ }^{(3)}$.

Existen distintos tratamientos quirúrgicos y no quirúrgicos, que se pueden plantear dependiendo del caso individual ${ }^{(3)}$. 
El nevus piloso congénito gigante presenta una incidencia de 1 por cada 30.000 a 100.000 personas $^{(7)}$. No se ha podido establecer un patrón de herencia familiar ${ }^{(1,8)}$, sin embargo alteraciones en la proteína HGE/SF (Factor de Crecimiento de Hepatocitos/Factor de Dispersión según sus siglas en inglés) parecen ser las responsables de que estas células neuroectodérmicas se desarrollen, migren y se dispersen ${ }^{(8)}$.

Los nevus congénitos gigantes presentan células névicas con tendencia a localizarse alrededor de los anexos y los vasos, infiltrando la dermis profunda y el tejido celular subcutáneo ${ }^{(4)}$.

La degeneración maligna puede ocurrir a cualquier edad, sin embargo es más común en niños e infantes. El 50\% de los melanomas se desarrollan a los 2 años de edad ${ }^{(3,8)}$ y el $80 \%$ para los siete años, siendo generalmente mortal. Es por esto que se recomienda su resección temprana ${ }^{(8)}$, preferiblemente luego de los 6 meses de vida, para reducir los riesgos quirúrgicos y estéticos ${ }^{(5)}$. Sin embargo, la literatura indica que estos pacientes pueden morir de cáncer aún cuando su nevus gigante haya sido removido, por ejemplo de melanoma del cordón espinal ${ }^{(8)}$, leptominges $\mathrm{u}$ otras zonas del $\mathrm{SNC}^{(9,10)}$.

Dentro del grupo de tratamientos no quirúrgicos se encuentran el tratamiento expectante, la irradiación, crioterapia y laserterapia.

Como métodos quirúrgicos que pueden realizarse están las resecciones seriadas, escisión y cobertura con injertos, expansión tisular, curetaje, dermoabrasión o electrocoagulación. Empero, no existe un consenso respecto al tratamiento de esta patología ${ }^{(3)}$.

\section{CONCLUSIONES}

El nevus piloso gigante es una rara condición, de presentación variada ${ }^{(2,3)}$.

Presenta riesgo de malignización, variando hasta $42 \%$ en ciertas series ${ }^{(3)}$, sin embargo al ser de difícil diagnóstico se recomienda su remoción completa profiláctica a temprana edad ${ }^{(4)}$.

Existen distintos tratamientos para eliminar el nevus piloso gigante ${ }^{(3)}$. En este caso se realizó una resección por segmentos con la ayuda de expansores tisulares para realizar el recubrimiento de las zonas extirpadas, con piel normal.

Mediante varias intervenciones quirúrgicas en las cuales se realizaron resecciones seriadas y avance tisular, se eliminó el $100 \%$ del nevus lumbar gigante y luego de cinco años de seguimiento, se da de alta a la paciente.

\section{BIBLIOGRAFÍA}

1. Riou G. Nevus gigante congénito. Les Nouvelles Dermatologiques 2002;21(10): 490-497.

2. Vera-Remartínez EJ García-Guerrero J. Nevus congénito pigmentado piloso gigante. Rev Esp Sanid Penit 2011;13:112-113.

3. Carneiro Junior LV Souza Aguiar L Pitanguy I. Tratamiento cirúrgico do nevo melanocítico gigante. Rev Bras Cir Plást 2011;26(2):198-204.

4. Peniche J. Capítulo 18: Tumores de la Piel en "Lecciones de Dermatología”, Amado Saúl. Pp: 619-620.

5. Grichnik J Rhodes A Sober A. Chapter 122: Benign Neoplasias and Hyperplasias of Melanocytes en "Fitzpatrick's Dermatology in General Medicine”. Pp:1377-1383.

6. García Morán JJ Jarabo García MT. Nevus Melanocíticos Congénitos: un estudio de 23 casos en un centro de salud. An Esp Pediatr 1996;44:545-547.

7. Paredes Moreno $\mathrm{G}$ Atiencia Hinojosa $\mathrm{S}$ Rivero Salmon C. Nevo piloso gigante congénito. Medicina (Guayaquil). 2006;11 (4):333-336.

8. Hashmi GS Ahmed SS Khan S. Congenital giant melanocytic nevi. Rare Tumors 2009;22:1(1)I:e9. doi:10.408/rt.2009.e9.

9. Giménez López V Monge Galindo L López Pisón J Zandueta Pascual L Clavero Montañés N Muñoz Mellado A. Melanosis neurocutánea. An Pediatr (Barc) 2011;75:224227.

10. Tincopa Wong O Muro Castro M. Nevus melanocítico congenito gignate, hypertension endocraneana y somnolencia. Dermatología Peruana 2003;13(3):234-243. 